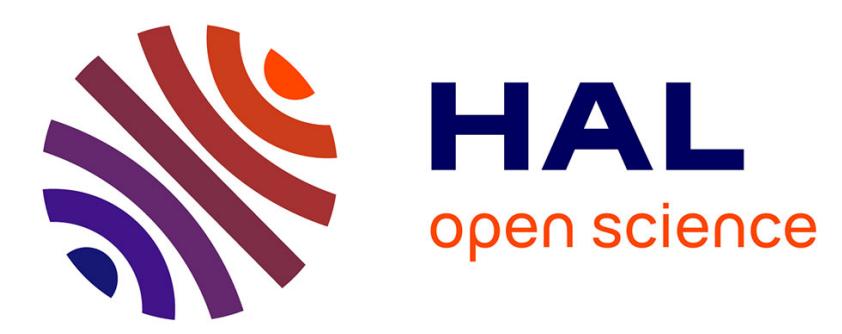

\title{
Adam Smith on lotteries: an interpretation and formal restatement
}

\author{
Laurie Bréban, André Lapidus
}

\section{To cite this version:}

Laurie Bréban, André Lapidus. Adam Smith on lotteries: an interpretation and formal restatement. European Journal of the History of Economic Thought, 2019, 26 (1), pp.157-197. 10.1080/09672567.2019.1576057 . hal-00914222v3

\section{HAL Id: hal-00914222}

\section{https://hal-paris1.archives-ouvertes.fr/hal-00914222v3}

Submitted on 27 Sep 2020

HAL is a multi-disciplinary open access archive for the deposit and dissemination of scientific research documents, whether they are published or not. The documents may come from teaching and research institutions in France or abroad, or from public or private research centers.
L'archive ouverte pluridisciplinaire HAL, est destinée au dépôt et à la diffusion de documents scientifiques de niveau recherche, publiés ou non, émanant des établissements d'enseignement et de recherche français ou étrangers, des laboratoires publics ou privés. 


\title{
Adam Smith on Lotteries: An Interpretation and Formal Restatement
}

\author{
Laurie Bréban* and André Lapidus**
}

This version: June 2018

\begin{abstract}
The paper concerns a neglected aspect of the Wealth of Nations (with the notable exception of D. Levy 1999), dealing directly with decision under risk. In a few pages from book I, chapter 10, Adam Smith explicitly named "lotteries" various objects of choice (possible occupations, or investment opportunities, for instance), and provided an analysis which standard expected utility glasses would hardly fit. Taking this into account allows a better understanding of the part played by typical characters like the "projector" or the "sober man", in such matters as Smith's conception of entrepreneurship or of the credit market. The use of some modern concepts in decision analysis (inverse stochastic dominance, rank dependent utility, prudence toward risk), is a means to show the existence, in Smith's work, of an original theory from decision under risk, where his analysis of lotteries in the Wealth of Nations is consistent with statements from his moral philosophy on asymmetric sensitivity to gains and losses and to the regulating part played by the impartial spectator.

Keywords: Adam Smith, decision, risk, lotteries, stochastic dominance, rank-dependent utility, asymmetric sensitivity, prudence.

JEL classification: B12, B31, D01, D81.
\end{abstract}

\section{Introduction}

This paper aims at highlighting what may be viewed as Adam Smith's analysis of decision under risk. A notable feature of this analysis is that it explicitly refers, both literaly and conceptually, to a notion of "lottery" not that dissimilar to the one currently used in modern decision theory. Smith understood lotteries in a broad sense, in a manner with which we today would be familiar, that is, not only as institutionalized gambles but also as various situations of choice under risk. From this point of view, Smith's work might be considered as a landmark in the "classical probability theory" which L. Daston (1988) considered being a component of the intellectual project of the Enlightenment. As such, classical probability appears to lie at the juncture of two legacies. One of them inherits the seventeenth's century mathematical calculus of chance; but the second reaps the reward of long reflection by medieval lawyers on the degrees of proof, far remote from the calculus of chance in gambles. Jacob Bernoulli's posthumously published Ars Conjectandi (1713), especially in part IV on moral, civil, and economic affairs (see I. Hacking 1971), and David Hume's Treatise on Human Nature (Hume 1739-40) which discusses philosophical and unphilosophical probabilities in book I, part III, both illustrate the beginning of this tradition, in which Adam Smith occupies an eminent place. But, from another point of view, though it might be argued that this classical probabilities tradition opened the path to what was to be known, since the middle of the last century, as the "expected utility" approach, Smith's contribution clearly pointed in an alternative direction.

A contemporary reader might find it curious that evidence concerning Smith's analysis of behavior under risk is first rooted in a section of the Wealth of Nations (section 1 of chapter 10, book I) which aims at providing an explanation of income differentials "arising from the nature of the employments themselves" (WN, I, 10, a, 2). ${ }^{1}$ Such evidence can also be drawn from other parts of the Wealth of

\footnotetext{
*PHARE, University Paris 1 Panthéon-Sorbonne - 106-112, boulevard de l'Hôpital - 75647 Paris Cedex 13 - France. E-mail: laurie.breban@univ-paris1.fr

** PHARE, University Paris 1 Panthéon-Sorbonne - 106-112, boulevard de l'Hôpital - 75647 Paris Cedex 13 - France. E-mail: andre.lapidus@univ-paris1.fr

${ }^{1}$ Adam Smith's works are abbreviated as follows (see complete references in the bibliography): TMS = Theory of Moral Sentiments; $W N=$ Wealth of Nations; LJ $=$ Lectures on Jurisprudence (A and B respectively refer to the manuscript from 1762-1763 and to the manuscript dated 1766). References are given according to the divisions of the Glasgow edition.
} 
Nations. It echoes the prior investigations from the Lectures on Jurisprudence, and is decisively related to statements from the Theory of Moral Sentiments. As a result, beyond the light that Smith's analysis from book I, chapter 10 of the Wealth of Nations sheds on the theory of wages, it gives rise to more general statements, illustrated by a wide variety of examples. Smith introduces, for instance, the "lottery of the law" (WN, I, 10, b, 22-6) which represents a particular case of a lottery of "liberal professions", as compared to the lottery of "mechanic trades" (WN, I, 10, b, 22); public lotteries (WN, I, 10, b, 26-7); the "lottery of the sea", as compared to the one of the soldier (WN, I, 10, b, 30-2); and even the "lottery of the church" (WN, I, 10, c, 35). A little later, in the section on income differentials "occasioned by the policy of Europe" (WN, I, 10, c), he comes again to the question of a lottery of mines $(W N, \mathrm{I}, 10$, c, 27), which he previously dealt with in the Lectures on Jurisprudence $(L J(\mathrm{~A})$, vi, $68 ; L J(\mathrm{~B}), 226-7)$, comparing it to a corn lottery, the same question being raised again in chapter 7 on colonies of book IV ( $W N$, IV,7, a, 17). The presentation of the central argument in the first section of chapter 10 has given rise to reluctant or, on the contrary, to immoderate praise, respectively illustrated by the clear-cut, though poorly argumented positions of J. Schumpeter and M. Blaug. On the one hand, J. Schumpeter's balanced judgment on Smith's contribution can be found again in his conclusion that "[t]his is the kind of thing in which A. Smith both delighted and excelled. The lead had been given by Cantillon. But A. Smith went much more deeply into the matter, thus creating an important if not exactly exciting chapter of the nineteenth-century textbook" (Schumpeter 1954, p. 258). And, on the other hand, M. Blaug's more favourable appraisal is reflected in his claim that "[u]ntil fairly recently, these pages in Smith and a few pages in Marshall's Principles exhausted the content of the history of economic analysis of choice among unsure prospects" (Blaug 1962, p. 47). ${ }^{2}$ However, although Smith's emphasis on the part played by risk in the choice of various employments was taken quite seriously by his contemporaries (see Bentham's comments in his Defence of Usury, especially his letter 13 to Adam Smith from March 1787, in Smith, Correspondence, p. 398), modern commentators like A. Rees (1975, p. 343) only considered it as leading to a kind of argument which is the "hardest to follow", in order to explain wage differentials.

It's obvious that, for an economist familiar with usual analysis of decision in risk, Smith's position might seem to discourage further investigation. D. Levy (1999), who tried to explore the analytical dimension of Smith's analysis through an expected utility approach, escaped such discouragement and made a notable effort to account for Smith's conceptions. Methodologically in line with Levy's contribution, we question the mutual consistency of Smith's various propositions regarding behaviors under risk, as found in the Wealth of Nations, the Lectures on Jusrisprudence, and the Theory of Moral Sentiments. But unlike Levy, we provide textual evidence which shows that this consistency is far from obvious, at least within the usual approach to decision under risk: it looks as if Smith was trying to put together statements regarding attitude toward risk (risk seeking, according to various examples given in the Wealth of Nations), decreasing sensitivity to increasses in the quantity of pleasurable things (which suggests a representation of desire through a concave function), and the over-valuation of the probabilities of gains, coupled to the under-valuation of the probabilities of loss (which Smith called an "absurd presumption"), which cannot stand together within an expected utility framework. Exploring the conditions and the analytical context which make Smith's various statements meaningful and consistent therefore requires a non-naïve use of what we know today about decision under risk, in order to stray away from the expected utility framework favored by D. Levy. This led us to proceed in three steps.

The first step (§2) focuses on the passages from the Wealth of Nations (mainly, but not exclusively, from book I, chapter 10) which introduce and discuss various examples of situations of choice under risk. In each of these situations, Smith establishes a relationship between what he calls "fairness" (the complete redistribution of the outlay among the gamblers, such that for each of them the expected return is equal to the initial outlay), risk and decision. He explicitly uses fairness in order to compare lotteries, pointing out that those which are usually preferred can be understood as the riskier ones.

However, Smith's argument shows that such attractiveness of risk covers two different ideas, which intuitively correspond to a preference given to a lottery in which the mass of probabilities has moved

(i) from the middle to the tails of the distribution (typically, the lottery of the law, when compared to that of the shoemaker) or, more specifically,

(ii) to the right tail from both the middle and the left tail of the distribution (the lottery of the army, when compared to that of the sea).

These two kinds of lotteries are interpreted hereafter in terms of inverse stochastic dominance (K.

\footnotetext{
${ }^{2}$ A more qualified point of view can be seen in contributions on risk which favor a historical perspective. P.-C. Pradier, for instance, is clearly aware of what is at stake in Smith's approach which compares fair and unfair lotteries, but he considers that it is of no consequence at a macroscopic level, and that it is so linked to moral philosophy, that it will not be taken up among Smith's followers (see Pradier 2006, pp. 28-30).
} 
Zaras 1989) of, respectively, degree two and degree three, type 2 (§2).

In an expected utility framework, such preference for riskier lotteries expresses a risk-seeking attitude which is conveyed by the convexity of the underlying valuation function. Now, such a reading of Smith's examples as typical illustrations of risk-seeking behavior within an expected utility framework would render inconsistent the author's propositions from the Wealth of Nations on behavior under risk, and from the Theory of Moral Sentiments on sensitivity to gains and losses, which give rise to a concave underlying valuation function (Bréban 2012). A path of reconciliation can be found by adopting a rankdependent utility approach, along the lines of what J. Quiggin initiated as early as 1982. Contrary to expected utility, such a perspective allows taking into account the individual weighting of probabilities and, accordingly, Smith's emphasis, in the Wealth of Nations, on a universal tendency to overestimate the chance of gain and, correlatively, to underestimate the chance of loss. This gives consistency to the behavior of some figures described in the Wealth of Nations, like that of the "projector" (§3).

Yet, such picture of the Smithian theory of decision under risk, built on what Smith says about lotteries and about asymmetric sensitivity to gains and losses, though faithful, still misses a key feature. Despite its universality, the tendency to overestimate the chances of gain is presented by Smith as challenged by a certain category of individuals, typically illustrated in the Wealth of Nations by another figure of the capitalist entrepreneur, namely that of the "sober man". In order to grasp the attitude of such individuals, we come back to Smith's analysis of prudence, chiefly presented in the Theory of Moral Sentiments. This shows that the issues related to decision under risk are integrated into a more general perspective, which aims at explaining the evolution of typical decision patterns by contrasting two points of view - the "natural" one and that of the "impartial spectator": following Smith, prudent behavior consists in overcoming our "natural" tendency by adopting the point of view of an "impartial spectator", in order to avoid what he calls "hazard" (TMS, VI, i, 6), that is, situations involving chances of losses. On the one hand, such an attitude toward risk is similar to what we have also been used to calling "prudence" since the work of M. Kimball (1990). But on the other hand, prudence also helps understand how a preference for riskier lotteries can turn into a preference for riskless ones (§4).

\section{A methodological addendum}

We are aware that such extensive use of concepts from decision theory requires further explanation. Some of them, like "lotteries" or "prudence" toward risk, have a curious similarity to Smith's own vocabulary. Obviously, though, we do not claim that his own phrases coincided in meaning with ours. For instance, it doesn't make sense to credit Smith with a formal understanding of lotteries as a discrete random variable, that is as a mapping from a finite set of the states of the world into a set of consequences. Nonetheless, when Smith writes about, say, the lottery of the soldier, he imagines alternative situations, which we view as alternative states of the world, and military ranks, which stand for consequences. So we feel able to represent the relation between them by means of a random variable: the "lottery", in Smith's words, can be accounted for by a "lottery", as a discrete random variable.

Other concepts from decision theory, like "stochastic dominance", have no terminological equivalent in Smith's words. Yet, when Smith compares lotteries - for instance, what he calls the "lottery of the soldier" and the "lottery of the sea" -, he doesn't give an isolated single statement, whose scope would be restricted to the lotteries compared. The preference given to the lottery of the soldier comes as an example, referring to a general disposition which determines choices among lotteries. This general disposition leads to comparing both distributions in terms of their possible outputs and probabilities, discussing their respective probabilities of reaching at least such-and-such a rank, either in the army or in the navy. Though in an informal way, Smith compares the distribution functions of the two lotteries, and he is interested in their relative spreads and deformations. This provides us with sufficient basis to see the kind of order between lotteries described by Smith as a stochastic dominance order.

But now, what is the point of such an approach?

In the above-noted passages from the Wealth of Nations and from the Theory of Moral Sentiments, Smith gives some general statements concerning decision, inferred from examples or illustrated by them. Their compatibility affects the relation between his two major works through the relation between attitude toward risk and sensibility to gains and losses, and also through the part played by the virtue of prudence in order to explain the evolution of the attitude toward risk from the "natural" to the "impartial spectator's" point of view. But Smith didn't explicitly discuss the compatibility between these statements. Schematically, this has given rise to three kinds of reactions:

1. For most commentators, it was not a problem: they deliberately ignored this topic, considering that Smith's relevance to the history of economics was to be found elsewhere. 
2. For others, the account of what Smith says didn't open a path to the clear identification of his different statements on the topic and, as a result, did not lead to the discussion of their compatibility (see, for instance, Rees 1975).

3. Finally, a few commentators interpreted Smith through an expected utility approach (see Levy 1999).

Our use of formal analysis challenges each of these reactions. It aims at:

A. building a framework in which Smith's statements can be seen to be sensible and compatible (answer to 2.);

B. showing that it cannot therefore be a naïve or explicit expected utility theory (answer to 3.) - which obviously requires the use of a consistent formal framework;

C. supporting the claim that although Smith was usually acknowledged for his contribution to other topics in economics, he also made an outstanding contribution to the analysis of decision (answer to 1.).

\section{Fairness, risk, and lotteries}

When commenting on the pages from the Wealth of Nations dedicated to lotteries (mainly, I, 10, b), D. Levy (1999) reads Smith through expected utility glasses. Yet there are good reasons to give up this assumption in favor of a representation more appropriate to Smith's treatment of behavior under risk. In the early stages, indeed, it is not even necessary to have recourse to an alternative representation: within all of what Smith says concerning decision under risk, much might be viewed today as a "model-free" discussion - that is, a discussion involving neither expected nor non-expected utility representations. The basis of this discussion is a curious metaphor which runs from the Lectures on Jurisprudence to the Wealth of Nations through which Smith considers not only gambles strictly speaking, but also decisions concerning the choice of an occupation, insurance or investment, as various types of "lotteries" (see references supra, p. 2).

\subsection{Lottery of the state, insurance, and lottery of the law: weak risk-seeking}

The lottery metaphor leads Smith to define - at first sight quite accurately - what he calls a "perfectly fair lottery" as a lottery "in which the whole gain compensated the whole loss" (WN, I, 10, b, 27) or, in other words, a lottery where the total outlay is redistributed among the gamblers. At the gambler's level, a "perfectly fair lottery" is such that his expected gain equals the price he is asked to pay for gambling. Denoting $L=\left(x_{1}, x_{2}, \ldots x_{i}, \ldots x_{n} ; p_{1}, p_{2}, \ldots p_{i}, \ldots p_{n}\right)$ the distribution of a discrete random variable (a "lottery") where the $x_{i}$ and $p_{i}$ are the respective outcomes (ranked in increasing order) and probabilities $\left(p_{1}+p_{2} \ldots+p_{i} \ldots+p_{n}=1\right)$ of a state of the world $i$, and $x_{0}$ the outlay,

$$
\text { Perfect fairness } \Leftrightarrow x_{0}=E(L)
$$

Now, Smith is quite explicit about the fact that the "world neither ever saw, nor ever will see, a perfectly fair lottery", and for each example which follows this assertion, he explains which kind of unfair lottery prevails. For instance, he argues that "[i]n the state lotteries the tickets are really not worth the price which is paid by the original subscribers" ( $W N, \mathrm{I}, 10, \mathrm{~b}, 27)$. The case of the lottery of the law is quite significant. Smith depicts a "counsellor at law who, perhaps, at near forty years of age, begins to make something by his profession". Had the lottery of the law been a fair lottery, he should have received "the retribution, not only of his own so tedious and expensive education, but of that of more than twenty others who are never likely to make any thing by it". However, Smith explains, "[h]ow extravagant soever the fees of counsellors at law may sometimes appear, their real retribution is never equal to this" ( $W N, \mathrm{I}$, $10, \mathrm{~b}, 22$ ). And many other examples lead to the same conclusion concerning the properties of an unfair lottery - that the price paid to participate in this lottery is greater than its expected outcome:

$$
\text { Unfairness } \Leftrightarrow x_{0}>E(L)
$$

(Note that Smith does not really take up here the case complementary to (1) or (2), nowadays more familiar, where $x_{0}<E(L)$, which could be viewed as another type of unfairness).

When Smith discusses the case of the student in law, of the subscriber to a state lottery, of the neglect of insurance upon shipping or upon houses, of the young man who decides to become a soldier, of the 
silver mines undertaker, he points out that we are living in a world of unfair lotteries. And the fact that we are inclined towards such unfair lotteries should not be underestimated. It means that when we are faced with the alternative "participate in an unfair lottery $L$ and paying for this $x_{0}>E(L)$ " or "do not participate in this lottery and keeping the outlay $x_{0}$ within one's purse", many of us would prefer to participate. Since we accept to pay $x_{0}$, this means that we prefer $L$ to $x_{0}$ and, acknowledging that preferences are monotone, that we prefer $L$ to $E(L)$. In other words, we are weakly risk-seeking (WRS). Denoting $\succ$ the strict preference which constitutes the asymmetric part of the binary relation of preference $\succeq$ over the set $\Lambda$ of (possibly degenerated) lotteries and, by abuse of notation, $E(L)$ the lottery which gives a certain outcome equal to the expected value of $L$, this attitude means that

$$
\text { WRS: } \forall L \in \Lambda(\text { with } L \neq E(L)), L \succ E(L)
$$

Something which might initially be viewed as a judgement about fairness (an unfair lottery is a lottery whose expected value is inferior to the value of the outlay) now appears as an attitude toward risk (WRS) for those who accept, at least potentially, an unfair exchange (pay less for a lottery than the expected value of this lottery). And it is well known that such an attitude does not require, per se, any particular kind of functional representation of preferences over lotteries like, for instance, expected utility or any alternative. That is to say that weak risk-seeking WRS (3) can be seen as model-free.

Similar conclusions can be drawn from what Smith says about the demand for insurance. He observes the low proportion of private houses or ships which benefit from insurance:

Taking the whole kingdom at an average, nineteen houses in twenty, or rather perhaps ninetynine in a hundred, are not insured from fire. Sea risk is more alarming to the greater part of people, and the proportion of ships insured to those not insured is much greater. Many sail, however, at all seasons, and even in time of war, without any insurance (WN, I, 10, b, 28).

On some occasions, Smith explains, this might be justified because several uncorrelated risks constitute some kind of mutual insurance:

When a great company, or even a great merchant, has twenty or thirty ships at sea, they may, as it were, insure one another. The premium saved upon them all, may more than compensate such losses as they are likely to meet with in the common course of chances. (Ibid.).

But usually such is not the case: most people refuse to pay a "common premium [...] sufficient to compensate the common losses" (Ibid.), which would make a fair lottery of insurance business ${ }^{3}$. Since the insurance premium is the difference between the value of the good insured and the certainty equivalent of the lottery, it means that the certainty equivalent, $x^{*}$, is greater than the expected value $E(L)$ of this lottery. Consequently, the risk premium $\rho(L)$ (the difference between the expected value and the certainty equivalent) should be negative. Now, we know (see, for instance, M. Cohen 1995, p. 75) that an agent for whom

$$
\forall L \in \Lambda, \rho(L)<0
$$

is also weakly risk-seeking, so that (3) and (4) are equivalent. State lotteries, as well as the demand for insurance, both display the same attitude toward risk. However, a model-free approach restricted to weak risk-seeking such as expressed in (3) makes the comparison between lotteries a bit flimsy. After all, it only allows comparing a lottery $L$ with a degenerated lottery which gives with certainty an outcome $x>E(L)$, and concluding that there are some $x$ to which $L$ is preferred. This allows us to say that such a risky situation is preferred to some other riskless situation, but it doesn't say anything about preferences between different risky situations - that is, between two different non-degenerated lotteries $L_{a}$ and $L_{b}$. In other words, weak risk-seeking does not say a great deal about the intuition of an increase in risk - which M. Rothschild and J. Stiglitz (1970) described as strong risk-seeking.

\subsection{Lottery of the law, again: second-degree inverse stochastic dominance}

Smith does not limit his analysis to what we would call "weak risk-seeking", that is, to the comparison between a risky and a certain outcome. He also proceeds to comparisons between differently risky lotteries. Other examples, still through Smith's attempt to grasp the meaning of a fair lottery, show that he goes further: he compares unfair lotteries not only to certain outcomes, but also to other unfair lotteries, one of them usually approaching "nearer to a perfectly fair one" (WN, I, 10, b, 27). Again, an initial

\footnotetext{
${ }^{3}$ Rigorously speaking, one might argue that there is a difference, at least from the potential insured point of view, since Smith adds that he also has to "pay the expence of management" and a profit at a normal rate $(W N, \mathrm{I}, 10, \mathrm{~b}, 27)$.
} 
judgement on fairness leads to a judgement on risk differentials, and finally to the identification of an attitude towards risk. In most of his examples, Smith depicts an individual who prefers unfair to less unfair lotteries: he prefers to try to become a lawyer, rather than a shoemaker ( $W N, \mathrm{I}, 10, \mathrm{~b}, 25)$; he buys tickets for a state lottery with "great prizes", but he neglects these less unfair lotteries where "no prize exceeded twenty pounds" ( $W N, \mathrm{I}, 10, \mathrm{~b}, 27)$; he chooses to become a soldier, where he could have been a sailor, whereas "the lottery of the sea", Smith says, "is not altogether so disadvantageous as that of the army" (WN, I, 10, b, 31).

Here again, the case of the "lottery of the law" is a possible key to understanding Smith's way of proceeding to compare two lotteries, different according to fairness and to risk. He contrasts the situation of the lottery of the law, and another lottery, of "mechanick trades" or of "common trade, such as that of shoemakers or weavers" (WN, I, 10, b, 22). Let us call these two lotteries respectively $L_{a}=\left(x_{a 1}, x_{a 2} ; p_{a 1}, p_{a 2}\right)$ and $L_{b}=\left(x_{b 1}, x_{b 2} ; p_{b 1}, p_{b 2}\right)$. For $i=a, b, x_{i 1}$ and $p_{i 1}$ denote the respective net outcomes (that is, outcome minus outlay) and probabilities in case of failure, and symmetrically, $x_{i 2}$ and $p_{i 2}$ are the net outcomes and probabilities in case of success. Of course, $p_{i 1}+p_{i 2}=1$. Now, Smith does not only give his reader the required details in order that he understands that the student in law is weakly risk-seeking. He also notices that whereas for a student in law, the probability of becoming such a highly respected counsellor is very low, the probability of success is much higher for more common occupations: "Put your son apprentice to a shoemaker", Smith says, "there is little doubt of his learning to make a pair of shoes" (WN, I, 10, b, 22). And in counterpart, he contrasts the "so tedious and expensive education" (Ibid.) of the student in law, when compared to that of this apprentice shoemaker. His balance between fair and unfair lotteries in the same paragraph shows that the lotteries of the law and of the common trade are, respectively, clearly unfair for the first and, if not completely fair, close enough to a fair lottery for the second. In other words,

$$
\begin{aligned}
& x_{a 1}<x_{b 1}, x_{a 2}>x_{b 2}, p_{a 2}<p_{b 2}, \text { such that } \\
& E\left(L_{a}\right)<0 \text { and } E\left(L_{b}\right)=0
\end{aligned}
$$

But the comparison between the two lotteries is not as simple as it might seem on first view. Through a kind of thought experiment, Smith shifts from the initial unfair lottery $L_{a}$ to a hypothetically fair lottery of the law (denote it $L_{a}^{\prime}$ ). Imagining a redistribution in favor of the high outcome, he claims that $L_{a}^{\prime}$ is a simple modification of the initial unfair lottery $L_{a}$, obtained by an increase in its higher outcome $x_{a 2}$ : the expenses of the twenty students in law who failed, Smith says, should be added to the retribution of the one who succeeds $(W N, \mathrm{I}, 10, \mathrm{~b}, 22)$. Since $L_{a}$ and $L_{a}^{\prime}$ are identical except in the case of success, where $x_{a 2}^{\prime}>x_{a 2}$, any individual whose preferences are monotone would prefer $L_{a}^{\prime}$ to $L_{a}$, whatever his or her attitude toward risk. More generally, this means that for each outcome $x$, obtaining at most $x$ is more probable with initial lottery $L_{a}$ than with the modified lottery $L_{a}^{\prime}$, and strictly more probable for at least one $x$ (actually, for each $x \in\left[x_{a 2}, x_{a 2}^{\prime}\right]$.

This can be stated more conveniently in the terms of stochastic dominance (for an introduction to stochastic dominance, see, for instance, H. Levy 2006). Define the cumulative and the decumulative distribution function of a discrete random variable $X$ as, respectively, $F(x)=\operatorname{Prob}(X \leq x)$ and $\bar{F}(x)=$ $\operatorname{Prob}(X \geq x)$. First-degree stochastic dominance $(F S D)$ of a lottery $L_{F}$ over $L_{G}$ is defined by $F(x)-$ $G(x) \leq 0$ for all $x$ (with strict inequality for at least one $x$ ), and it amounts to saying that any individual whose preferences are monotone prefers $L_{F}$ to $L_{G}$. It is therefore obvious that, if $F_{a}(x)$ and $F_{a}^{\prime}(x)$ are the cumulative distribution functions of $L_{a}$ and $L_{a}^{\prime}, \forall x \in\left[x_{a 1}, x_{a 2}^{\prime}\right]$,

$$
\begin{aligned}
& \forall x \in\left[x_{a 1}, x_{a 2}^{\prime}\right], \\
& F_{a}^{\prime}(x)-F_{a}(x) \leq 0 \text { and } F_{a}^{\prime}(x) \neq F_{a}(x) \Leftrightarrow L_{a}^{\prime} F S D L_{a}
\end{aligned}
$$

And, for this very reason, $L_{a}^{\prime}$ is (strictly) preferred to $L_{a}^{4}$ :

$$
L_{a}^{\prime} F S D L_{a} \Rightarrow L_{a}^{\prime} \succ L_{a}
$$

${ }^{4}$ The use of first-degree stochastic dominance plays a crucial part in the appraisal of Smith's comparison between an initial $\left(L_{a}\right)$ and a hypothetical modified $\left(L_{a}^{\prime}\right)$ lottery, because $F S D$ leads to preferences independent from the attitude toward risk. Such is clearly not the case, for instance, when $L_{a}$ is a state lottery, and $L_{a}^{\prime}$ a "lottery in which no prize exceeded twenty pounds", though their probability is higher and $L_{a}^{\prime}$ comes closer to a perfectly fair lottery $(W N$, p. 125$)$. This time, the expected value of the lottery is modified not through an increase in the highest outcome, but through a decrease in the outcome and an increase in its probability. It would be easy to check that, in such a situation, $L_{a}^{\prime}$ does not first-degree stochastically dominate $L_{a}$ any more, since for all $x$ belonging to $] x_{a 2}^{\prime}, x_{a 2}\left[, F_{a}^{\prime}(x)-F_{a}(x)>0\right.$. However, $L_{a}^{\prime}$ second-degree stochastically dominates $L_{a}(S S D)$, because for all $x$ belonging to $\left[x_{a 1}, x_{a 2}^{\prime}\right]$, the expression $H_{2}(x)=\int_{x_{a 1}}^{x}\left[F_{a}^{\prime}(t)-F_{a}(t)\right] d t \leq 0$. And Smith rightly concludes from his comparison that "there would not be the same demand for tickets" ( $W N$, p. 125). Indeed, although all risk-averters would prefer the modified lottery $L_{a}^{\prime}$ to the initial state lottery $L_{a}$, other people (a majority, according to Smith), among which risk-lovers, would prefer $L_{a}$ to $L_{a}^{\prime}$. 


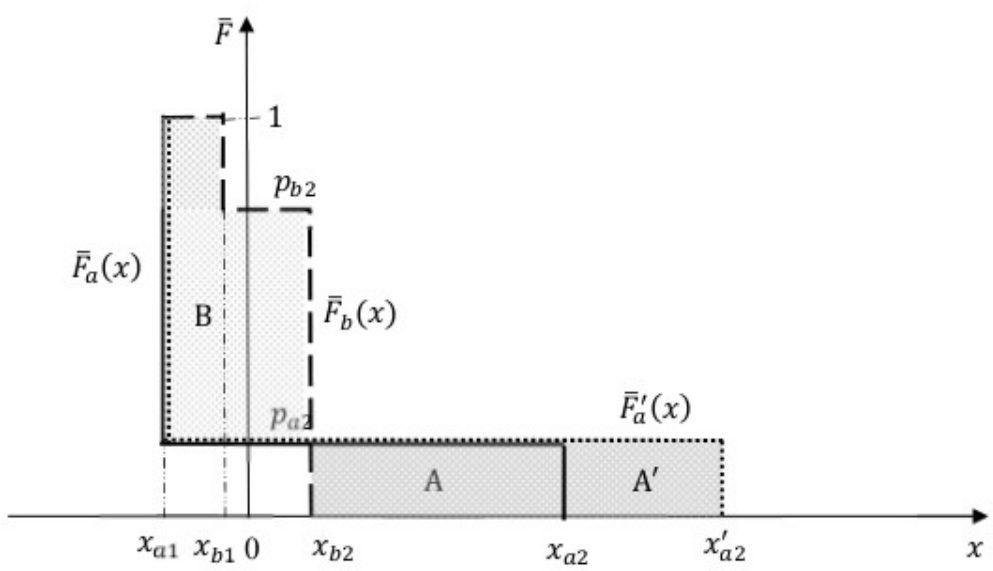

Figure 1: Decumulative distribution functions: the lottery of the law $L_{a}$, the hypothetical fair lottery of the law $L_{a}^{\prime}$, the lottery of common trades $L_{b} . E\left(L_{a}\right)<E\left(L_{a}^{\prime}\right)=E\left(L_{b}\right) ; L_{a}^{\prime} S I S D L_{b} ; L_{a}^{\prime} F S D L_{a}$

Turning now to the comparison between $L_{a}^{\prime}$ and the lottery of common trade $L_{b}$, there is no difference between them concerning their respective fairness, since both of them can be considered to be lotteries in which the net outcomes are the results from a redistribution of the total outlays between the gamblers. According to Smith's previous explanations on the cost of the studies in law and on the probability of success, the hypothetical lottery of the law $L_{a}^{\prime}$ is a spread (and, since $E\left(L_{a}^{\prime}\right)=E\left(L_{b}\right)$, a mean-preserving spread, $M P S$ ) of the lottery of the common trade $L_{b}$, since high outcomes are still higher in $L_{a}^{\prime}$, but they are less probable, whereas low incomes are still lower in $L_{a}^{\prime}$, and also more probable:

$$
\begin{aligned}
& L_{a}^{\prime} \operatorname{MPSL}_{b}: \\
& \qquad x_{a 1}^{\prime}=x_{a 1}<x_{b 1} ; x_{a 2}^{\prime}>x_{b 2} ; p_{a 2}^{\prime}=p_{a 2}<p_{b 2} ; E\left(L_{a}^{\prime}\right)=E\left(L_{b}\right)=0
\end{aligned}
$$

This intuition is rigorously expressed by the concept of second-degree inverse stochastic dominance (SISD), introduced by M. Goovaerts et al. (1984). The expected values of both lotteries being equal (8), the condition for $S I S D$ of $L_{a}^{\prime}$ over $L_{b}$ is given by:

$$
\begin{aligned}
& \forall x \in\left[x_{a 1}, x_{a 2}^{\prime}\right] \\
& \bar{H}_{2}(x)=\int_{x}^{x_{a 2}^{\prime}}\left[\bar{F}_{a}^{\prime}(t)-\bar{F}_{b}(t)\right] d t \geq 0 \text { and } \bar{F}_{a}^{\prime}(t) \neq \bar{F}_{b}(t) \Leftrightarrow L_{a}^{\prime} S I S D L_{b}
\end{aligned}
$$

Though they are identical under the aspect of fairness, the hypothetical lottery of the law is riskier than the lottery of the common trade, in the sense where $L_{a}^{\prime}$ is second-degree inverse stochastically dominating $L_{b}$. As shown in Figure 1 where the decumulative distribution functions of $L_{a}, L_{a}^{\prime}$ and $L_{b}$ are represented, condition (9) is satisfied since, because of (8), the area of $A+A^{\prime}$ is equal to the area of $B$.

For the individual depicted by Smith, who is getting ready to study law, $L_{a}^{\prime}$, which is riskier than (though as fair as) $L_{b}$, would be also (strictly) preferred to it:

$$
L_{a}^{\prime} S I S D L_{b} \Rightarrow L_{a}^{\prime} \succ L_{b}
$$

Since this is a preference for a mean-preserving spread (8), it also expresses attractiveness for the kind of increase in risk understood as strong risk-seeking (SRS):

$$
\text { SRS : } L_{a}^{\prime} M P S L_{b} \text { and } L_{a}^{\prime} \succ L_{b}
$$

This might be interpreted as a change, resulting from Smith's thought experiment, in the starting point of the analysis. Imagine that the initial choice is not between $L_{a}$ and $L_{b}$, but between $L_{a}^{\prime}$ and $L_{b}$. Allowing continuity of preferences, it is obviously the very existence of a strict preference in favor of the riskier lottery $L_{a}^{\prime}$ which leaves room for the possibility of a preference over the lottery of common trade $L_{b}$ given to some other lotteries, not as $\operatorname{good} \operatorname{as} L_{a}^{\prime}$ :

$$
L_{a}^{\prime} S I S D L_{b} \Rightarrow \exists L_{a}: E\left(L_{a}\right)<0, L_{a}^{\prime} F S D L_{a}, \text { and } L_{a} \succ L_{b}
$$


A risk-seeking attitude expressed by (10) has now allowed the introduction of an unfair lottery $L_{a}$ which anybody should consider worse than $L_{a}^{\prime}$, and that the individual described by Smith considers better than $L_{b}$.

This contributes toward making explicit the kind of relation that Smith establishes between fairness, risk, attitude toward risk, and preferences between lotteries. The hypothetical fair lottery of the law is just as fair as the lottery of the common trade: both can be viewed as lotteries in which a same total outlay is redistributed among gamblers, although the former is riskier, in the sense of second-degree inverse stochastic dominance, than the latter. When this increased risk gives rise to preferences, it also opens the path to the possibility, for some lotteries which are first-degree stochastically dominated by the hypothetical fair lottery of the law, to be nonetheless preferred to the lottery of the common trade. Such is the case for the effective lottery of the law. This latter, now, is clearly less fair than the hypothetical fair lottery of the law and, therefore, also less fair than the lottery of the common trade. In other words, it is not because a lottery is riskier than another that it is also less fair. But it is because a riskier lottery is preferred to a less risky one that there is room for giving preference to an unfair lottery, like that of the law, over a fair or nearly fair lottery, like that of common trades.

The above mentioned examples of the state lotteries or of the demand for insurance can be interpreted in the same way. If $x_{0}$ is the price of the ticket for a hypothetical lottery $L^{\prime}$ such that $E\left(L^{\prime}\right)=x_{0}, L^{\prime}$ is a fair lottery. Because of weak risk-seeking (3), $L^{\prime}$ would be preferred to $x_{0}$, and it is obvious that $L^{\prime} S I S D x_{0}$. Now, this preference given to the riskier option allows the possibility for a lottery $L$, such that $L^{\prime} F S D L$ (for instance, diminish the higher outcome in $L^{\prime}$ to build $L$ ), to be preferred to $x_{0}$. And because $L^{\prime} F S D L$ implies $E(L)<E\left(L^{\prime}\right)=x_{0}$, preference is given to an unfair lottery.

\subsection{The lottery of the army: third-degree inverse stochastic dominance of the second type}

Among Smith's other examples, some illustrate the same approach which makes the preference for an unfair lottery an effect of a risk-seeking attitude expressed by second-degree inverse stochastic dominance. Some of his examples, but not all: these complications show that although Smith had risk-seeking in mind, second-degree inverse stochastic dominance is at times insufficiently selective in the characterization of possible risk-seeking attitudes. This leads to the introduction of some kind of prudent risk-seeking attitude, in that it expresses the intuitive idea of an individual being all the more risk-seeking that the possible gain is important, and conversely all the less risk-seeking that the possible loss is important. It should be emphasized that this does not mean that this individual would be somehow less risk-seeking, but that he is risk-seeking in a particular way. In standard analysis, for instance, this might refer to an individual who is interested in increasing not only the variance, but also the skewness of a distribution (the second and the third central moment). He would therefore favor a spread to the right tail of the distribution (to increase the variance), and a contraction from the left tail (to increase the skewness). Rigorously, this is represented by third-degree inverse stochastic dominance of the second type (see Goovaerts et al. 1984 and Zaras 1989).

An example of these complications appears when Smith moves to the question of knowing why "common people [...] enlist as soldiers, or go to sea" (WN, I, 10, b, 29), which gives rise to a comparison between these two unfair lotteries, the "lottery of the sea [being] not altogether so disadvantageous as that of the army" (WN, I, 10, b, 31). At first sight, this looks very much like the example of the lottery of the law and the lottery of the common trades - the first one standing for the lottery of the army (denote it again $L_{a}$ ) and the second for the lottery of the sea $\left(L_{b}\right)$. A difference seems to come from the fact that there is a wider range of payoffs for each lottery. Ranking them in increasing order, this means that in each case, one might (i) be killed in action; (ii) stay a simple soldier or sailor; (iii) become an officer; (iv) be promoted to the highest rank.

Smith barely discusses the lowest outcomes. Everyone, among his readers, knows what they are: death in each case, to which Smith refers discreetly when he says that "[w]hat a common soldier may lose is obvious enough" ( $W N, \mathrm{I}, 10, \mathrm{~b}, 30$ ), adding a little further that the possible positive outcome of the lottery in which he is involved is "the whole price of [his] blood" (Ibid.); or, concerning sailors, when he brings up the "dangers and hair-breadth escapes of a life of adventures" (WN, I, 10, b, 32). He is still less explicit concerning this danger, and he does not seem to mark any difference concerning the probability of death for a soldier and for a sailor. But for all other outcomes, it seems better to be in the army than in the navy:

The great admiral is less the object of publick admiration than the great general, and the highest success in the sea service promises a less brilliant fortune and reputation than equal 
success in the land. The same difference runs through all the inferior degrees of preferment in both. By the rules of precedency a captain in the navy ranks with a colonel in the army: but he does not rank with him in the common estimation. (WN, I, 10, b, 31).

Whatever the reasons put forward, they aim at explaining why so many young people prefer to be a general than an admiral, a colonel in the army than a captain in the navy, and a simple soldier than a simple sailor, whose hard life is described in detail (Ibid.). But this difference is challenged by the probabilities of the respective outcomes of the two lotteries:

As the great prizes in the lottery are less, the smaller ones must be more numerous. Common sailors, therefore, more frequently get some fortune and preferment than common soldiers (Ibid.).

This means that whereas there is a greater probability of becoming an admiral than a general, a captain in the navy than a colonel in the army, there is a lesser probability of remaining a simple sailor than a simple soldier.

The difference between the lottery of the army and the lottery of the sea on the one hand, and the lottery of the law and the lottery of common trades on the other hand, now becomes more conspicuous. When you move from the lottery of common trades to the lottery of the law, your greater possible gain becomes both higher and less probable - like when you move from the lottery of the sea to the lottery of the army, where you might become a colonel instead of a captain, a general instead of an admiral. But what for the lower ranks? In the worst case, you die, and it doesn't seem that there is one among the two lotteries in which it would be undoubtedly less probable. If you chose the army, remaining a private is more probable than remaining a sailor in the navy: this still looks like the lotteries of the law and of common trades. But your life would be better as a soldier than as a sailor, and that is contrary to the lowest respective outcomes of the lotteries of the law and of common trades. In the lottery of the law, you exchange the possibility of a greater higher outcome for a smaller probability and a smaller and more probable lower outcome. In the lottery of the army, you still exchange the possibility of a greater higher outcome for a smaller probability. But it is not that great since, in counterpart, your lower outcome, though still more probable in the army, is now higher and not smaller.

Smith's argument might be captured more easily by simplifying the number of ranks he refers to. Assume that, here again, there are only two possible couples of net outcomes for each lottery $L_{a}$ and $L_{b}$ : $x_{a 1}$ with probability $p_{a 1}$ stands for the outcome of, say, the soldier, $x_{a 2}$ with probability $p_{a 2}$ for that of the general; $x_{b 1}$ with probability $p_{b 1}$ stands for the outcome of the sailor, $x_{b 2}$ with probability $p_{b 2}$ for that of the admiral (for $i=a, b, p_{i 1}+p_{i 2}=1$ ).

To sum up, the respective values of the outcomes and probabilities in the lotteries $L_{a}$ and $L_{b}$ are such that:

$$
\begin{aligned}
& x_{a 1}>x_{b 1}, x_{a 2}>x_{b 2} ; p_{a 2}<p_{b 2} ; \\
& E\left(L_{a}\right)<E\left(L_{b}\right)<0
\end{aligned}
$$

The fact that either the lottery of the army or the lottery of the sea might be chosen although they are unfair, and although other occupations, closer to a fair lottery, are available, shows that the individual concerned is weakly risk-seeking.

Nonetheless, pursuing the same approach as with the lotteries of the law and of common trade does not provide what might have been expected. Let us transform the lottery of the army in the same way, from $L_{a}$ to $L_{a}^{\prime}$, that is, to a hypothetical lottery of the army where the retribution of the general is increased until it becomes as fair as the lottery of the sea. It is obvious that, here also, (6) and (7) are satisfied so that $L_{a}^{\prime} F S D L_{a}$, and would be universally preferred to the initial lottery of the army (everybody who aims at becoming a general would prefer to be a better-paid general). Turning to the respective characteristics of $L_{a}^{\prime}$ and $L_{b}$, they are now:

$$
\begin{aligned}
& x_{a 1}^{\prime}=x_{a 1}>x_{b 1}, x_{a 2}^{\prime}>x_{a 2}>x_{b 2} ; p_{a 2}^{\prime}=p_{a 2}<p_{b 2} ; \\
& E\left(L_{a}^{\prime}\right)=E\left(L_{b}\right)<0
\end{aligned}
$$

Contrary to the lotteries of the law and of the common trade, the graphs of the decumulative distribution functions $\bar{F}_{a}^{\prime}$ and $\bar{F}_{b}$ in Figure 2 clearly show that $L_{a}^{\prime}$ cannot be second-degree inverse stochastically dominating $L_{b}$ : as a result of (14), $A+A^{\prime}<B$ so that condition (9) is not fulfilled. However, provided the lotteries do not give comparatively a too high outcome to the soldier or a too low outcome to the general, and given the equality of the expected values of both lotteries (14), conditions of third-degree 


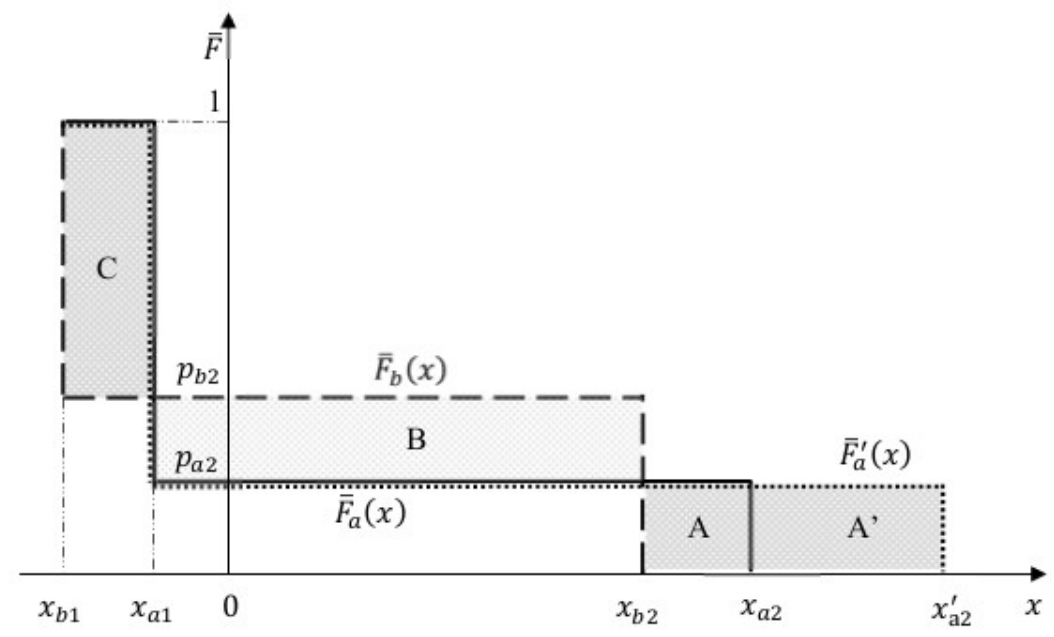

Figure 2: Decumulative distribution functions: the lottery of the army $L_{a}$, the hypothetical fair lottery of the army $L_{a}^{\prime}$, the lottery of the sea $L_{b} . E\left(L_{a}\right)<E\left(L_{a}^{\prime}\right)=E\left(L_{b}\right) ; L_{a}^{\prime} T I S D 2 L_{b} ; L_{a}^{\prime} F S D L_{a}$

inverse stochastic dominance of the second type (TISD2; see Goovaerts et al. 1984, Zaras 1989) from $L_{a}^{\prime}$ on $L_{b}$ are satisfied:

$$
\begin{aligned}
& \forall x \in\left[x_{b 1}, x_{a 2}^{\prime}\right], \\
& \bar{H}_{3}(x)=\int_{x}^{x_{a 2}^{\prime}} \bar{H}_{2}(t) d t \geq 0 \text { and } \bar{F}_{a}^{\prime}(t) \neq \bar{F}_{b}(t) \Leftrightarrow L_{a}^{\prime} T I S D 2 L_{b}
\end{aligned}
$$

The intuitive meaning of TISD2, where $\bar{H}_{3}(x) \geq 0$ in (15), is that $L_{a}^{\prime}$ results from a spread of the high outcomes of $L_{b}$ and a contraction of its low outcomes, so that risk is both increased and transferred from lower to higher outcomes. And the individual who strictly prefers enlisting in the army to joining the navy is risk-seeking in the sense of TISD2:

$$
L_{a}^{\prime} T I S D 2 L_{b} \Rightarrow L_{a}^{\prime} \succ L_{b}
$$

Like in the case of the lottery of the law, the equalization of fairness between the hypothetical lottery of the army and the lottery of the sea allows preference for the riskier. And it is, again, in this interval between both lotteries, that there is room for some lotteries first-degree stochastically dominated by $L_{a}^{\prime}$, like the initial lottery of the army $L_{a}$, which can be preferred to that of the sea:

$$
L_{a}^{\prime} T I S D 2 L_{b} \Rightarrow \exists L_{a}: E\left(L_{a}\right)<E\left(L_{b}\right), L_{a}^{\prime} F S D L_{a} \text {, and } L_{a} \succ L_{b}
$$

\subsection{Limits to a model-free approach}

What Smith says about fair and unfair lotteries has opened the path to a model-free interpretation of the attitude toward risk of those who prefer unfair lotteries, in terms of second-degree inverse stochastic dominance, or third-degree inverse stochastic dominance of the second type. Yet, giving up this modelfree approach through what seems the easiest way, an expected utility representation, would be rather intuitive: stochastic dominance establishes meaningful relations between the different kinds of dominance and the properties of the underlying function which gives rise to expected utility. Consider the following convex sets of underlying functions:

$$
\begin{array}{ll}
U^{1}=\left\{u: u^{\prime}>0\right\} & \text { (increasing functions) } \\
U^{12}=\left\{u: u^{\prime}>0, u^{\prime \prime} \geq 0\right\} & \text { (increasing convex functions) } \\
U^{123}=\left\{u: u^{\prime}>0, u^{\prime \prime} \geq 0, u^{\prime \prime \prime} \geq 0\right\} & \text { (increasing convex functions with } \\
& \text { non-decreasing convex first derivative) }
\end{array}
$$

$L_{a}$ and $L_{b}$ are two lotteries, whose expected utility are noted respectively as $E_{U}\left(L_{a}\right)$ and $E_{U}\left(L_{b}\right)$. The following results allow linking an attitude toward risk, expressed by stochastic dominance, and preferences 
over lotteries, expressed by expected utility ${ }^{5}$ :

$$
\text { If } L_{a} F S D L_{b} \text {, then } E_{U}\left(L_{a}\right) \geq E_{U}\left(L_{b}\right), \forall u \in U^{1}
$$

(Hadar and Russel 1969; Hanoch and Levy 1969)

$$
\text { If } L_{a} S I S D L_{b} \text {, then } E_{U}\left(L_{a}\right) \geq E_{U}\left(L_{b}\right), \forall u \in U^{12} \subset U^{1}
$$

(Goovaerts et al. 1984)

$$
\text { If } L_{a} \text { TISD2 } L_{b} \text {, then } E_{U}\left(L_{a}\right) \geq E_{U}\left(L_{b}\right), \forall u \in U^{123} \subset U^{12} \subset U^{1}
$$

(Goovaerts et al. 1984; Zaras 1989)

The conclusion seems straightforward. Since SISD and TISD2 are required in order to give an account of the attitudes toward risk which Smith points out when he moves to the analysis of lotteries, the expected utility hypothesis leads to a representation of choices by means of the corresponding functions belonging to $U^{12}$ or to its subset, $U^{123}$. Typically, this would mean that, in the case of the choice between the lottery of the law and that of the common trade, where SISD prevails, all the increasing convex functions would be possible candidates, whereas no increasing concave function would be. These increasing convex functions would all express risk-seeking, through a notion which makes equivalent the various concepts of risk attitude which might be distinguished in a model-free context (see Rothschild and Stiglitz 1970): convexity of the utility function is equivalent to strong risk-seeking, to weak risk-seeking, and to the existence of a negative risk premium. In the case of the choice between the lottery of the army and that of the sea, TISD2 just leads to reduce the set in which any utility function might represent it to a subset $U^{123}$ of $U^{12}$. Obviously, the already noticed equivalences would still hold, but with the supplementary characteristic that risk-seeking is increasing with $x$. Therefore, it seems that the only remaining problem is to make sure that among such a wide range of possibilities, one of them at least is not contradicted by what Smith says about decision.

The point is that the range of possibilities is still too narrow, so that, as shown in section 3 hereafter, none of them fits Smith's position.

\section{The "absurd presumption": over- or under-valuation of chances}

In the Theory of Moral Sentiments, Smith argued in favor of an asymmetric sensitivity to favorable and unfavorable events (TMS, I, iii, 1, 3). It is tempting to interpret this in terms of a "loss aversion principle", à la D. Kahneman and A. Tversky (1979; see P. Wakker (2010)), like in N. Ashraf, C. F. Camerer and G. Loewenstein (2005). Nonetheless, as one of us pointed out (Bréban 2012), this interpretation (and, more generally, a reference-dependent approach to Smith) lacks textual evidence. In this case, asymmetric sensitivity rather refers to a function which plays the same part as a standard utility function whose propriety of concavity or convexity depends on the position on a social scale of happiness: when an individual's permanent state of happiness is close to its highest level, the function is concave, otherwise it is convex. And since in most cases, according to Smith, people are closer to the highest level of happiness, the function is usually concave: a favorable event is assumed to have a smaller impact on enjoyment than the symmetrical unfavorable one. This means that $u$ should be an increasing concave function:

$$
u \in U_{2}^{1}=\left\{u: u^{\prime}>0, u^{\prime \prime} \leq 0\right\}
$$

(Bréban 2012)

As a result, $u$ can obviously belong neither to the set of increasing convex functions $U^{12}$ nor, a fortiori, to its subset $U^{123}$. And since risk-seeking, in an expected utility approach, would require the convexity of the underlying function (like in (18b) or (18c)), such an approach seems of no help for giving an account of what Smith says about choice among lotteries. This issue is the one which M. Allais raised as early as 1953, when criticizing expected utility theory: the same property (concavity or convexity) cannot express both valuation of preferences (cardinal utility) and an attitude toward risk.

\subsection{Can we keep up the expected utility interpretation?}

An ingenious way to by-pass this difficulty would be to argue that some other elements in Smith's analysis, left aside till now, lead us to question the very relevance of risk-seeking for such situations as the choice

\footnotetext{
${ }^{5}$ A systematic account of results concerning the links between stochastic dominance, direct and indirect up to degree 3 , and the properties of the utility function, can be found in Zaras (1989) and (except for TISD1 and TISD2) in H. Levy (2006), chap. 3 who provides both necessary and sufficient conditions.
} 
of a professional occupation, so that a standard, risk-averse expected utility approach might be favored.

When comparing liberal professions with mechanic trades, Smith acknowledges various possible reasons for the success of the former. Seemingly, he accepts two of them:

First, the desire of the reputation which attends upon superior excellence in any of them; and, secondly, the natural confidence which every man has more or less, not only in his own abilities, but in his own good fortune. (WN, I, 10, b, 23).

Each of these reasons deals with a different matter:

- The "desire of reputation" concerns the motives for action, and comes to explain the success of liberal professions, whereas they "are, in point of pecuniary gain, evidently under-recompenced" relatively to "mechanick trades" (WN, I, 10, b, 22).

- The "natural confidence" deals with individual's ability to evaluate situations. It also comes to explain the success of liberal professions, although "[i]n the greater part of mechanick trades, success is almost certain; but very uncertain in the liberal professions" (Ibid.). A closer examination shows that, according to Smith, natural confidence applies to two different topics $(W N, \mathrm{I}, 10, \mathrm{~b}, 26)$ :

- "the over-weening conceit which the greater part of men have of their own abilities",

- and "the absurd presumption in their own good fortune",

the last one, alone, being relevant for his analysis of choices under risk.

Concerning the first issue, the "desire of reputation" allows Smith to explain the success of liberal professions by pointing out that "pecuniary gains" are not the sole reward of such professions, since reputation, or what he also calls "public admiration", might constitute the greatest part of their outcome:

The publick admiration which attends upon such distinguished abilities, makes always a part of their reward; a greater or smaller in proportion as it is higher or lower in degree. It makes a considerable part of that reward in the profession of physick; a still greater perhaps in that of law; in poetry and philosophy it makes almost the whole (WN, I, 10, b, 24).

This position is a long-lasting one for Smith, and was, as noted by the editors of the Wealth of Nations, already present in the Lectures on Jurisprudence. This might suggest that the lottery of the law is not that unfair and that, possibly, the novice poet or lawyer is not more risk-seeking than the novice shoemaker. Such an interpretation seems to have been favored by D. Levy (1999) who uses the "desire of reputation" argument in order to reconcile an expected utility approach with Smith's discussion of lotteries.

Our interpretation would be rather that this plays the same part as Smith's shift to a hypothetically fair lottery, when he imagines that the expenses of twenty unsuccessful students in law are added to the retribution of the only one who succeeds: no need to imagine a fair lottery, since it actually exists! This is unambiguously confirmed by what he had already said in the Lectures:

The ten or twelve therefore who come into business must have wage(s) not only to compensate the expence of their education, which is very great as a man must be 30 years or thereabouts before he can be of any service as a lawyer, but also the risque of not being ever able to make any thing by it. The temptation to engage in this or any other of the liberall arts is rather the respect, credit, and emin(en)ce it gives one than the profit of it. Even in England where they are more highly rewarded than any where else, if we should compute them according to the same rule as that of a smith or other artizan they would be still rather too low. But the honour and credit which attends on them is to be considered as a part of the wages and a share of the reward $(L J(\mathrm{~A}), \mathrm{vi}, 61-2)$.

Consider again the lottery of the law: on the one hand, it is now as fair as the lottery of the shoemaker; but on the other hand, it is also a mean-preserving spread of this lottery, so that it dominates it stochastically in the sense of $S I S D$. Consequently, the utility function which might be used to represent the choices of the lawyer or of the poet should still belong to the set of increasing convex functions: the compatibility between Smith's position and an expected utility approach is not that easy to obtain. 


\subsection{The "absurd presumption" in one's own good fortune}

The first issue - desire of reputation - reinforces the negative argument against the expected utility interpretation: taking it into account confirms that an expected utility framework does not fit with Smith's claims concerning both valuation of preferences and attitude toward risk. Now, the decisive argument is a positive one, related to the second issue - natural confidence - which opens up an an alternative to an expected utility approach. After having distinguished natural confidence as a mental state from the nature of the motives involved in the choices between lotteries, Smith takes care to separate its two possible objects, which both contribute to explaining why a riskier lottery is chosen: natural confidence, either in one's "own abilities", or in one's "own good fortune" (WN, I, 10, b, 26). Moreover, although this last type of confidence might be related to this kind of belief which Hume called "unphilosophical probability" (Hume 1739-40, I, pp. 143-54; see M.-A. Diaye and A. Lapidus 2012), Smith stresses the novelty of his views on the estimation of the probabilities of gains and losses:

The over-weening conceit which the greater part of men have of their own abilities, is an antient evil remarked by the philosophers and moralists of all ages. Their absurd presumption in their own good fortune, has been less taken notice of. It is, however, if possible, still more universal. There is no man living who, when in tolerable health and spirits, has not some share of it. The chance of gain is by every man more or less over-valued, and the chance of loss is by most men under-valued, and by scarce any man, who is in tolerable health and spirits, valued more than it is worth. (WN, I, 10, b, 26)

In the opening discussion of the lottery of the law, Smith's claim for novelty appears to result from a specific rhetoric. Within this rhetoric, the desire of reputation and the overestimation of one's ability successively vanish in favor of what feeds the analysis of various types of lotteries which runs through this part of chapter 10: the over- or under-valuation of chances. Like the desire of reputation, the first component of natural confidence, the overestimation of one's own ability, does play an important part, since it concerns the consequences of actions (see Bréban 2011, pp. 249-63). However, this is clearly not the issue to which Smith tries to draw his reader's attention. The very mechanism which is at the core of our tendency to prefer unfair and riskier lotteries rests on a propensity to depart from probabilities, that Smith calls the "absurd presumption in [one's] own good fortune".

In spite of its alleged novelty, this mechanism seems quite intuitive: we have a tendency to overvalue probabilities of gains, and to under-value probabilities of losses $(W N, \mathrm{I}, 10, \mathrm{~b}, 28)$. Let us then take Smith's claim in a systematic way, and consider again a lottery like that of the army, but without aggregating the different ranks into two categories. We are now facing $n$ different ranks, which give rise to outcomes $x_{i}$ which increase from $x_{1}$ (say, a private), to $x_{n}$ (a general) with probabilities $p_{i}$ going similarly from $p_{1}$ to $p_{n}$. Let us focus on an intermediate rank $i$ - a captain, for instance. Because of his "presumption" in his "own good fortune", the candidate willing to join the army over-values his "chance of gain" (WN, I, 10, b, 26): the decision weight $\pi\left(x \geq x_{i}\right)$ which he associates to the possibility of obtaining at least the rank of a captain is greater than its probability $p\left(x \geq x_{i}\right)$. And consistently with what Smith says about the tendency to under-value lower outcomes, the decision weight associated to obtaining a rank lower than that of a captain, $\pi\left(x<x_{i}\right)=1-\pi\left(x \geq x_{i}\right)$, would be smaller than its probability $p\left(x<x_{i}\right)=1-p\left(x \geq x_{i}\right)$. In case this property holds for all ranks $i$ in the army (and assuming that the decision weight of a probability equal to 0 is also equal to 0 and that the decision weight of certainty is, like its probability, equal to 1), this closely follows Smith's argument on over- and under-valuation. Now define an increasing function $\varphi$ from $[0,1]$ into itself, which transforms the probability of obtaining an outcome at least as great as $x_{i}$ into its decision weight. The previous discussion means that:

$$
\pi\left(x \geq x_{i}\right)=\varphi\left(\sum_{j=i}^{n} p_{j}\right) \geq p\left(x \geq x_{i}\right)=\sum_{j=i}^{n} p_{j}
$$

(equality holds when $p\left(x \geq x_{i}\right)$ equals 0 or 1 )

Elementary decision weights $\pi_{i}$ can be easily derived from (20) as the difference between the decision weight of obtaining at least $x_{i}$, and the decision weight of obtaining at least $x_{i+1}$ :

$$
\begin{aligned}
& \pi_{i}=\pi\left(x \geq x_{i}\right)-\pi\left(x \geq x_{i+1}\right)=\varphi\left(\sum_{j=i}^{n} p_{j}\right)-\varphi\left(\sum_{j=i+1}^{n} p_{j}\right) \\
& \pi_{n}=\varphi\left(p_{n}\right)
\end{aligned}
$$


Always according to (20), $\varphi$ is such that for all $p$ in $[0,1], \varphi(p) \geq p$, the equality holding only when $p$ equals 0 or 1 . It is obvious that this amounts to saying that $\varphi$ is strictly concave, that is $\varphi^{\prime \prime}<0$. An immediate consequence of this property of $\varphi$ should be noted. Imagine two ranks $h$ and $k$, denoting for instance a sergeant and a colonel, such that $x_{h}<x_{k}$ and $p_{h}=p_{k}=\bar{p}$. The over-valuation of the chance of becoming a colonel, in comparison of that of becoming a sergeant, implies that $\pi_{h}<\pi_{k}$ or, according to (21), that a positive magnitude like its right member, $\varphi(p+\bar{p})-\varphi(p)$ is decreasing with $p$ (that is, increasing with the outcome, when moving from the sergeant to the colonel): because of the concavity of $\varphi$, though it is as probable to become a sergeant as it is to become a colonel, the decision weight of the former is smaller than that of the latter.

This interpretation of Smith's argument matches an idea introduced in the economic literature by J. Quiggin (1982), which is at the origin of the variety of models belonging to what has later become known as a "rank-dependent utility" approach (for an introduction focusing on associated risk perceptions see, among others, M. Cohen 2015). Dealing with cumulated, instead of elementary, probabilities has the advantage of avoiding the major drawback of an intuitive but rather crude representation based on the transformation of elementary probabilities (that is, $\pi_{i}=\varphi\left(p_{i}\right)$ ): the well-known possibility that the preferred lottery is first-degree stochastically dominated by a non-preferred lottery. Accordingly, Smith's intuition of a transformation of probabilities leads to a (rank-dependant) valuation $U(L)$ of a lottery ${ }^{6}$, now ensuring that preference for first-degree stochastically dominant lotteries will not be violated:

$$
\begin{aligned}
& U(L)=\sum_{i=1}^{n}\left(\pi_{i} u\left(x_{i}\right)\right) \\
& \text { where } \pi_{i}=\varphi\left(\sum_{j=i}^{n} p_{j}\right)-\varphi\left(\sum_{j=i+1}^{n} p_{j}\right) \\
& \left(\text { and } \varphi^{\prime}>0 ; \varphi(0)=0 ; \varphi(1)=1 ; \pi_{n}=\varphi\left(p_{n}\right)\right)
\end{aligned}
$$

It is obvious that here $\varphi$ plays a decisive part, since it determines the differences between decision weights and probabilities. For instance, strict concavity (which implies $\varphi(p)>p$ when $p$ is different from 0 or 1 ) or convexity $(\varphi(p)<p)$ of $\varphi$ respectively entail an over-valuation or an under-valuation of the probabilities of high outcomes and, symmetrically, an under-valuation or an over-valuation of the probabilities of low outcomes, currently interpreted as, respectively again, "optimism" or "pessimism" under risk (the limit case where $\varphi$ is both concave and convex, and transforms each probability in itself, corresponding to the situation where the individual is neither optimistic nor pessimistic under risk, and behaves according to a standard expected utility approach). Smith's idea of a specific transformation of probabilities, where those which are related to high outcomes increase whereas the ones which concern low outcomes decrease, might therefore be understood as "optimism" in this technical sense. It is expressed by:

$$
\varphi^{\prime \prime}<0
$$

Apart from formal aspects, the meaning of $\varphi$ is far from self-evident, and two alternative interpretations seem to arise. The first one is that the individual concerned has a false perception of probabilities $-\pi_{i}$ instead of $p_{i}$. The second interpretation is that although his perception of probabilities is correct (he is not mistaken about $p_{i}$ ), he nevertheless considers the different issues with more or less optimism or pessimism (which leads him to set the decision weight $\pi_{i}$ above or beneath $p_{i}$, in line with the value of $\varphi\left(\sum_{j=i}^{n} p_{j}\right)-\varphi\left(\sum_{j=i+1}^{n} p_{j}\right)$. Now, when Smith argues that we over-value or under-value probabilities, the words he uses clearly show that he favors the second interpretation. For instance, when he discusses the choice of a profession by "young people", he contrasts, on the one hand, probabilities, referred to by "misfortune" or "good luck", and, on the other hand, optimism or pessimism, referred to by "hope" or "fear":

The contempt of risk and the presumptuous hope of success, are in no period of life more active than at the age at which young people chuse their professions. How little the fear of

\footnotetext{
${ }^{6}$ In standard rank-dependent utility models, $U(L)$ is usually written:
}

$$
U(L)=u\left(x_{1}\right)+\ldots+\varphi\left(\sum_{i=j+1}^{n} p_{i}\right)\left[u\left(x_{j+1}\right)-u\left(x_{j}\right)\right]+\ldots+\varphi\left(p_{n}\right)\left[u\left(x_{n}\right)-u\left(x_{n-1}\right)\right]
$$

which is equivalent to $(22)$ (when $\varphi^{\prime}>0 ; \varphi(0)=0 ; \varphi(1)=1$ ). In order to keep notations consistent with those of the previous section, we have kept up the use of ranking outcomes in an increasing order, from the lowest outcome $x_{1}$ to the highest $x_{n}$. Nonetheless, in recent literature, rank-dependent utility models usually favor notations in which outcomes are ranked in a decreasing order. 
misfortune is then capable of balancing the hope of good luck, appears still more evidently in the readiness of the common people to enlist as soldiers, or to go to sea (WN, I, 10, b, 29; our italics, L.B and A.L.).

Smith's argument is rather sophisticated. He explains that focusing only on probabilities (misfortune, or good luck) would lead a young man to move away from the army or from the navy, like from studying law. When he takes fear and hope into account, he does not become ignorant of these probabilities. But this brings out a widely spread discrepancy between decision weights and probabilities, so that the army, the navy, and studying law, can become attractive.

According to this last interpretation, each decision weight conveys the combination of two elements: probability strictly speaking, and the correlative pessimism or optimism under risk (fear and hope, in Smith's words). The resulting attitude toward risk hence results from both the effect of the intensity of preferences (asymmetric sensitivity), expressed through the concavity or convexity of the underlying function $u$, and the optimism or pessimism expressed, again, by the concavity or convexity of $\varphi$. Insofar as the individual is sufficiently optimistic ( $\varphi$ is concave enough), he can be weakly risk-seeking despite the concavity of $u$ (see the conditions given by A. Chateauneuf and M. Cohen 1994, p. 89). Since only WRS is concerned, this would support Smith's position on our willingness to buy tickets for an unfair lottery (see above, (3)), but it does not say anything on more complex choices between lotteries, like these of the law and of the shoemaker. Yet we have dealt with these more complex choices, arguing that they give rise to a preference for inverse stochastically dominating lotteries ((12), (17)). But the results are a bit disappointing if we insist on considering that for the student in law, for instance, all the mean-preserving spread lotteries (like the hypothetically fair lottery of the law) are preferred to the initial lottery (that of the shoemaker) - that is, if preference between equally fair lotteries (with equal means) is always granted to the second-degree inverse stochastically dominating one, which corresponds to strong risk-seeking (SRS, (11)), S.-H. Chew, E. Karni and Z. Safra (1987) have shown that in a rank-dependent utility model, SRS is equivalent to the convexity of the utility function and the concavity of the function of transformation of probabilities. Like in an expected utility framework, this means that we cannot get rid of the convexity of the utility function, and that SRS is not compatible with Smith's position on asymmetric sensitivity.

The solution rests on a refinement of the concept of risk-seeking involved. It is clear that WRS, which allows consistency between the concavity of $u$ and $\varphi$, is too demanding since it orders too few lotteries and that SRS (that is, SISD with mean-preserving spread), which does not allow consistency, is insufficiently demanding. So there is room for a subset of the set of pairs of lotteries ordered by SRS which would not forbid the concavity of $u$. A similar issue would also apply to lotteries ordered by TISD2. In the case of SRS, A. Chateauneuf, M. Cohen and I. Meilijson (2005) identified such a subset, linked to monotone risk-seeking (MRS), and gave a condition on $u$ and $\varphi$ which ensures that in spite of the concavity of $u$, optimism is high enough to generate (monotone) risk-seeking.

\subsection{An illustration}

The comparison between the lottery of the law and that of the shoemaker is a typical instance of the possibility of obtaining risk-seeking in spite of a greater sensitivity to unfavorable events. It might be viewed as a simple case (only two possible outcomes for each occupation), in which the lottery of the law $L_{a}^{\prime}$ is a (monotone) mean-preserving spread of the lottery of the shoemaker $L_{b}$ - provided the desire for reputation (supra, p. 12) or, equivalently, the hypothetical fair lottery (supra, p. 6) is taken into account - so that they share the same expected outcome $\left(E\left(L_{a}^{\prime}\right)=E\left(L_{b}\right)\right)$. This is a typical instance because in the framework of expected utility, giving preference to the lottery of the law over the lottery of the shoemaker would require the convexity of the utility function. On the contrary, Figure 3 and Figure 4 show how, in a rank-dependent utility framework, such a preference can be made consistent with a concave underlying function expressing asymmetric sensitivity to favorable and unfavorable events, like in Bréban (2012).

The respective probabilities of success in both lotteries, $p_{a 2}^{\prime}$ and $p_{b 2}$, are transformed (Figure 3) in decision weights $\pi_{a 2}^{\prime}$ and $\pi_{b 2}$, the former transforma ation being more important than the latter, because of the concavity of $\varphi(p)$, so that the decision weight of a success in studying law has proportionally increased much more than that of the success in becoming a shoemaker (and, conversely, for the respective decision weights of failure $\pi_{a 1}^{\prime}=1-\pi_{a 2}^{\prime}$ and $\pi_{b 1}=1-\pi_{b 2}$ ).

In Figure 4, because of the concavity of $u$, the expected utility $E_{U}\left(L_{a}^{\prime}\right)$ of the lottery of the law is smaller than that of the shoemaker $E_{U}\left(L_{b}\right)$, which contradicts the preference given to the former. But 


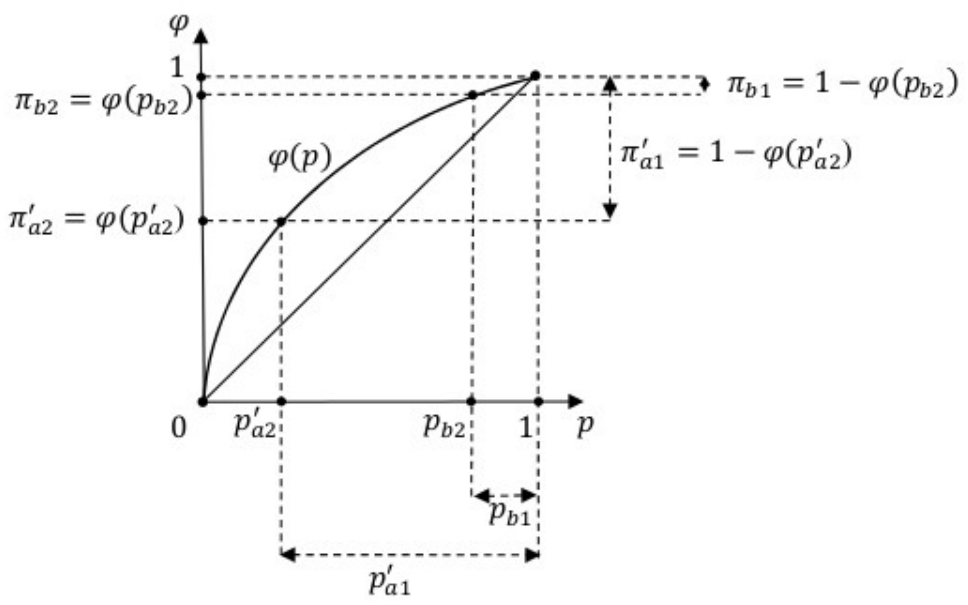

Figure 3: Lottery of the law and lottery of the shoemaker - The transformation of probabilities by fear and hope

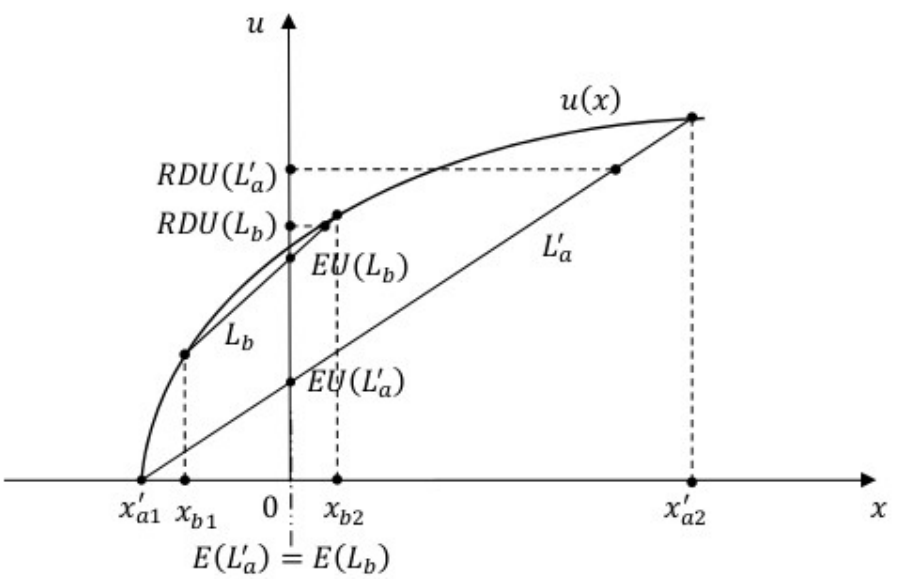

Figure 4: Lottery of the law and lottery of the shoemaker - Rank-dependent utility vs expected utility valuation

moving to the decision weights given in Figure 3 increases the valuation of $L_{a}^{\prime}$ to the detriment of that of $L_{b}$ in terms of rank-dependent utility $(R D U): R D U\left(L_{a}^{\prime}\right)>R D U\left(L_{b}\right)$.

In spite of a greater sensitivity to unfavorable events, it now makes sense to give preference to the riskier lottery, like the lottery of the law, or the lottery of the army, even if it is second-degree (or, in the case of the army, third-degree second type) inverse stochastically dominating the other lottery - that of the shoemaker, or of the navy.

\section{Toward a complete theory of behavior under risk}

This shows the consistency between two kinds of arguments on which Smith's conception of decision under risk relies:

- the first argument, principally developed in section 3, part I of the Theory of Moral Sentiments, concerns the widely spread asymmetric sensitivity to favorable and unfavorable events, according to which the latter have a more important effect than the former;

- the second argument, illustrated by the examples from chapter 10, book I of the Wealth of Nations, concerns the equally widely spread tendency to give preference to a riskier lottery, in the sense of second or some higher degree inverse stochastic dominance.

The solution can be found in a rank-dependent utility approach, which emphasizes a tendency which Smith also presents as universal: the overvaluation of the chances of gain, which comes along with an undervaluation of the chances of loss. As a result, individuals are led to commit to riskier and unfair situations, such as liberal professions, public lotteries or the army, whereas less risky and fairer 
opportunities are available. A great part of the former difficulties of interpretation of the few seemingly simple pages on lotteries comes from the fact that an intuitive expected utility approach definitely did not fit them.

\subsection{Smith on entrepreneurship: from projectors to sober men}

Once this interpretation is acknowledged, it can be extended in order to understand some of the various characters which appear in the Wealth of Nations. And among them, we may single out this category of capitalist entrepreneurs which Smith calls "projectors" (WN, II, 2, 64; II, 4, 15). These latter are involved in operations quite similar to unfair lotteries, needing significant capital and facing a high risk of bankruptcy, for which the amount of profit does not compensate (see, for instance, $W N, \mathrm{I}, 10, \mathrm{~b}, 33$; I, $10, \mathrm{~b}, 43)$. It is well known that Smith contrasts projectors with another category of entrepreneurs, "the sober people" (WN, II, 4, 15; V, 2, 12), who are said to be "strangers" to all these "hazardous projects of trade" $(W N, \mathrm{~V}, 2,12)$ where profit does not compensate the risk of bankruptcy, that is, to unfair and riskier lotteries.

As already noticed by several commentators (D. Levy 1987; S. Hollander 1999; S. Leloup 2000; M. P. Paganelli 2003), the source of the projectors' inclination toward these risky lotteries is the tendency to overestimate the chance of gain. It is therefore obvious that their behavior might be viewed as expressing sufficient optimism toward risk in a rank-dependent utility approach (see, for instance, $W N, \mathrm{I}, 10, \mathrm{~b}, 33$ ).

But a new difficulty arises: what about sober people? In other words, since we are dealing with such universal tendencies, why are there so few projectors, and so many sober people? Smith is quite clear in chapter 3 of book 2 of the Wealth of Nations:a

With regard to misconduct, the number of prudent and successful undertakings is everywhere much greater than that of injudicious and unsuccessful ones. After all our complaints of the frequency of bankruptcies, the unhappy men who fall into this misfortune make but a very small part of the whole number engaged in trade, and all other sorts of business; not much more perhaps than one in a thousand. Bankruptcy is perhaps the greatest and most humiliating calamity which can befall an innocent man. The greater part of men, therefore, are sufficiently careful to avoid it. Some, indeed, do not avoid it; as some do not avoid the gallows. (WN, II, 3, 29)

This requires another shift, back from the Wealth of Nations to the Theory of Moral Sentiments. Smith's already quoted description of sober people's behavior in the Wealth of Nations, as "strangers" to all "hazardous projects of trade" (WN, V, 2, 12), comes close to what he writes about the virtue of prudence in the Theory of Moral Sentiments, which leads us to avoid the possibility of unfavorable events ("any sort of hazard", Smith says; TMS, VI, i, 6). Bringing together sobriety (in the Wealth of Nations) and prudence (in the Theory of Moral Sentiments) makes visible the moral mechanism which governs the evolution of most entrepreneurs. Smith depicts the long-lasting internal struggle between what he calls our natural point of view and the point of view of the impartial spectator (see Bréban 2011, chap. 3, 4, 5; 2014). This duality of points of view refers to two alternative perceptions of an individual on his own situation. The natural point of view corresponds to his impulses and leads him to a disproportioned view of his own situation, whereas the impartial spectator's point of view is a moral device built on the basis of social interactions and internalised by the individual. And contrary to the natural point of view, the impartial spectator's point of view offers him a proper perspective on his situation. Usually, the latter overcomes the former, thanks to "self-command", which is a part of the virtue of prudence (TMS, IV, ii, 8). Transposed to the character of the capitalist entrepreneur, this means that although there is a natural tendency to over-value the chances of success, another kind of universality is also at work, so that the impartial spectator's point of view, which properly values the chances of success and failure, supersedes the natural one: the projector progressively puts an end to his over-valuing the probabilities of high outcomes, and becomes a sober man.

Stated more formally, this means that as the projector becomes sober, his decision weights come closer to the probabilities of the corresponding outcomes, up to the point that they match them. This, of course, implies a parallel evolution of the function $\varphi$ of transformation of probabilities: at the end of the process, when the individual is sober enough, there is no longer a difference between decision weights and probabilities, and $\varphi$ has become an identity function, which transforms each probability in itself. The behavior of the sober man might therefore be still represented by (22) but, instead of the properties defined by (23), the transformation function is such that

$$
\varphi^{\prime \prime}=0
$$


which clearly implies, along with (22), that $\pi_{i}=p_{i}$ for each $i$. In such a case, the difference between rank-dependent utility and expected utility vanishes: far from being meaningless with regard to Smith's conception of risk, this latter therefore happens to be the limit case for the sober man, when compared to projectors. Interestingly, though expected utility now appears as a convenient way to approach such behavior as that of the sober man, it is the result not of some rather demanding rationality assumption (the independence axiom), but of the working of a moral virtue, self-command, of which this demanding rationality is a possible consequence.

\subsection{The scope of prudence}

Leaving aside, as if it were some kind of black box, the details of the mechanism of self-command which leads the sober man from his natural point of view to the impartial spectator's point of view (see, however, a sketch of a formal representation in Bréban 2011, pp. 139-60), we focus rather on the formal implications of such behavior from the moment when the impartial spectator's point of view has been adopted. This leaves room for closer investigation of what might be viewed as the certainty component of the behavior of the sober man: his valuation of the intensity of preferences. We already know that $u$ is concave $\left(u^{\prime}>0\right.$ and $u^{\prime \prime} \leq 0$; see (19)), in order to express the greater sensitivity to unfavorable events. But pursuing the bringing together of the sober and the prudent man allows us to be more specific. Again in the Theory of Moral Sentiments, in an already mentioned passage from the first section of part VI, introduced in the 1790 sixth edition, Smith explicitly gives a supplementary content to the asymmetric sensitivity to favorable and unfavorable events:

We suffer more, it has already been observed, when we fall from a better to a worse situation, than we ever enjoy when we rise from a worse to a better. Security, therefore, is the first and the principal object of prudence. It is averse to expose our health, our fortune, our rank, or reputation, to any sort of hazard. It is rather cautious than enterprising, and more anxious: to preserve the advantages which we already possess, than forward to prompt us to the acquisition of still greater advantages. The methods of improving our fortune, which it principally recommends to us, are those which expose to no loss or hazard; real knowledge and skill in our trade or profession, assiduity and industry in the exercise of it, frugality, and even some degree of parsimony, in all our expences. (TMS, VI, i, 6)

In these few lines, Smith introduces the principal object of the virtue of prudence, "security", as an effect of our asymmetric sensitivity to favorable and unfavorable events ("We suffer more [...] when we fall from a better to a worse situation, than we ever enjoy when we rise from a worse to a better") and contrasts it with "hazard", which refers to the probability of the worst outcomes (an adverse event affecting "our health, our fortune, our rank, or reputation"). That is to say, prudence as a moral virtue also expresses a specific kind of aversion: not necessarily toward any kind of risk, but at least toward risk of loss.

Taking into account that, since his actions are in conformity with the point of view of the impartial spectator, the prudent or sober man behaves like an expected utility decision maker, this aversion does not concern decision weights, which could not move away from probabilities. It therefore concerns the valuation of preferences by $u$ itself. To avoid any confusion, we will refer to this hereafter as "embedded prudence".

Again, this is not an unfamiliar issue. First, because it takes the exact opposite view to, for instance, M. Yaari's dual theory of risk (Yaari 1987), according to which all information concerning attitude toward risk is embedded in the transformation of the probability function - and not in the function of payment which remains linear. Second, because arguing, like Smith, that for a prudent man a risk of loss is particularly to be avoided, echoes the idea that between two reductions in risk with mean-preserving spread, the one concerning losses and the other concerning gains, a prudent man will always prefer the former to the latter: without any reference to Adam Smith, this kind of attitude toward risk has also been called "prudence" by M. Kimball $(1990)^{7}$. Formally, it corresponds to a preference for third-degree stochastically dominating lotteries (TSD; see Whitmore 1970) and, in an expected utility framework, it means that the concavity of $u$ is all the more pronounced since the corresponding outcome is low. Or, still in other words, that the third derivative of $u$ is positive. This corresponds to a situation where the simple concavity of $u$ assumed in (19) is not restrictive enough to express embedded prudence, and should be replaced by:

$$
u \in U_{2}^{13}=\left\{u: u^{\prime}>0, u^{\prime \prime} \leq 0, u^{\prime \prime \prime} \geq 0\right\}
$$

${ }^{7}$ The same notion of "prudence" was previously identified as "downside risk-aversion" by C. Menezes, C. Geiss and J. Tressler (1980). A general framework has been described by L. Eeckhoudt and H. Schlesinger (2006). 
Obviously, (25) combined with an expected utility approach ((22)-(24)) gives an appropriate account of the prudent (and, consequently, of the sober) man's behavior.

But it might be argued that its extension is still wider and also concerns the imprudent man - here, the projector. This does not mean that, leaving risk aside, an individual, either prudent or imprudent, might be represented in the same way (Bréban 2011, pp. 273-88) but rather that, leaving aside with risk all other differentiating aspects like intertemporal preferences or the estimation of the consequences of actions, there is no reason why it should be represented differently. Since security is, for Smith, a consequence of an asymmetric sensitivity which grants a higher impact to unfavorable events (TMS, VI, i, 6 ), and since this type of asymmetry depends on the place of the individual's ordinary happiness within a social scale which goes from the "lowest depth of misery" to the "highest pitch of human prosperity" ( TMS, I, iii, 1, 8; see Bréban 2012), it does not depend on his attitude toward risk (for instance, projector or sober man), but only on his level of happiness. This already provides reasons to argue that a function with embedded prudence (25) represents the underlying function of intensity of preference of both the prudent and the imprudent man, the difference between them lying in the fact that, though a rankdependent utility approach can give an appropriate account of both behaviors, this approach vanishes into the particular case of expected utility for the former ((22)-(24)), and of (non-expected) rank-dependent utility for the latter ((22)-(23)).

But we also have other reasons. The example of the lottery of the army, compared to that of the sea, is of special interest. Contrary to the case of the lottery of the law compared to the lottery of common trades, the worst outcome (remaining a private or a sailor) corresponds to a better situation in the former lottery, which is also the preferred one. It has been shown (supra, pp. $8 s q q$ ) that such a preference might be explained by third-degree inverse stochastic dominance of the second type (TISD2). In a rank-dependent utility framework, it can be argued that this property depends not only on the function of transformation of probabilities $\varphi$ itself, but on the properties of $u$ which, although increasing and concave, also exhibits a non-negative third derivative, that is, embedded prudence like in (25). On an appropriate subset of the pair of lotteries ordered by TISD2, the concavity of $\varphi$ might therefore produce a risk-seeking attitude by overcoming the concavity of $u$. However, it might also respect the prudence involved in TISD2, so that risk-seeking appears as increasing with the outcome. On the contrary, in the case of the comparison of the lotteries of the law and of common trades, SISD supposes that the properties of $\varphi$ have also superseded the non-negativity of $u^{\prime \prime \prime}$.

\begin{tabular}{|c|c|c|c|}
\hline \multirow{2}{*}{$\begin{array}{l}\text { Examples } \\
\text { of characters: }\end{array}$} & \multirow{2}{*}{\multicolumn{2}{|c|}{$\begin{array}{c}\text { Projector } \\
\end{array}$}} & \multirow[b]{2}{*}{ Sober man } \\
\hline & & & \\
\hline Model free & $S I S D$ & TISD2 & $T S D$ \\
\hline$U(x) \in$ & \multicolumn{3}{|c|}{$U_{2}^{13}=\left\{u: u^{\prime}>0, u^{\prime \prime} \leq 0, u^{\prime \prime \prime} \geq 0\right\}$} \\
\hline $\begin{array}{l}\varphi^{\prime \prime} \text { - Attitude toward } \\
\text { probability }\end{array}$ & \multicolumn{2}{|c|}{$\begin{array}{c}<0 \\
\longrightarrow \text { Optimism }\end{array}$} & $\begin{array}{c}=0 \\
\longrightarrow \text { Neutrality }\end{array}$ \\
\hline \multirow{2}{*}{$\begin{array}{l}\text { Resulting attitude } \\
\text { toward risk }\end{array}$} & \multicolumn{2}{|c|}{ Risk seeking } & Risk aversion \\
\hline & \multicolumn{3}{|c|}{ Prudence } \\
\hline Moral point of view & $\longrightarrow$ & & $\begin{array}{l}\text { Impartial spectator } \\
\longrightarrow \text { Prudence }\end{array}$ \\
\hline
\end{tabular}

Table 1: A sketch of Smithian individuals' behavior under risk

If this interpretation is accepted, it would mean that most individuals (actually, all those whose ordinary state of happiness is high enough) are potentially prudent, because of the characteristics of their function of evaluation of preferences, which already displays embedded prudence (25). However, when they keep a natural point of view on their own situation, this potential prudence toward risk might be, in a context of risk-seeking, either hidden for some people who prefer dominating lotteries in the sense of SISD (lottery of the law, preferred to the lottery of the common trades), or disclosed, for all those who prefer dominating lotteries in the sense of TISD2 (lottery of the army, preferred to the lottery of the sea). But when they reach the point of view of the impartial spectator, the possibly contradictory action of $\varphi$ is suppressed, so that the embedded prudence involved in (25) always gives birth to prudence toward risk in the ranking of lotteries. These different elements are gathered in Table 1, which distinguishes among typical characters which appear within Smith's writings according to decisional characteristics related to moral categories. 


\section{Concluding remarks}

The developments devoted to lotteries in the Wealth of Nations, supplemented by the passages from the Theory of Moral Sentiments on asymmetric sensitivity to gains and losses and on prudence, give rise to some non-trivial propositions:

1. Preferences between lotteries can be expressed through a functional $R D U(L)=\sum_{i=1}^{n} \pi_{i} u\left(x_{i}\right)$ (see (22)) which combines

(a) a certainty component, $u\left(x_{i}\right)$ which reflects the intensity of preferences on possible outcomes;

(b) a risk component $\pi_{i}$ which, when different from probabilities $p_{i}$, shows how probabilities are transformed into decision weights.

2. The properties of the certainty component $u(x)$ depend on the position of the individual concerned in a social scale of happiness. For most individuals, it implies that $u$ is concave (greater effect of an unfavourable event; Bréban 2012), with a non-negative third derivative (embedded prudence, see $(25))$.

3. The decision weights $\pi_{i}$ (risk component) depend on a transformation of probabilities according to their ranks: $\pi_{i}=\varphi\left(\sum_{j=i}^{n} p_{j}\right)-\varphi\left(\sum_{j=i+1}^{n} p_{j}\right)$ with $\varphi(0)=0$ and $\varphi(1)=1$. The assumed concavity of $\varphi$ (optimism toward risk, in rank-dependent utility models) is an expression of the over-valuation of the chances of success and of the under-valuation of the chances of failure (see (23)), which Smith links to the balance between fear and hope.

4. The point of view of an individual on his own situation goes from the natural (imprudence) to the impartial spectator's (prudence) point of view (Bréban 2014), and determines his ranking of lotteries through the subsequent modifications of the risk component - and not of the certainty component. Attitudes toward risk of both typical points of view are characterized as follows:

(a) Natural point of view (imprudent individual; see (22), (25), (23))

$$
\begin{aligned}
& u: u^{\prime}>0, u^{\prime \prime} \leq 0, u^{\prime \prime \prime} \geq 0 \\
& \varphi: \varphi^{\prime}>0, \varphi^{\prime \prime}<0
\end{aligned}
$$

This allows for the risk-seeking attitude, in the sense of preference being given to dominating lotteries according to a subset of SISD ((9)) or TISD2 (where risk-seeking comes along with prudence toward risk; (15)), which Smith describes and illustrates in the pages on lotteries from the Wealth of Nations.

(b) Impartial spectator's point of view (prudent individual; see (22), (25), (24))

$$
\begin{aligned}
& u: u^{\prime}>0, u^{\prime \prime} \leq 0, u^{\prime \prime \prime} \geq 0 \\
& \varphi: \varphi^{\prime}>0, \varphi^{\prime \prime}=0
\end{aligned}
$$

This prudent behavior can be equivalently described either as a limit-case of rank-dependent utility with $\varphi^{\prime \prime}=0$, or through a standard expected utility approach with $\pi_{i}=p_{i}$, so that the properties of the utility function incorporate both prudence $\left(u^{\prime \prime \prime} \geq 0\right)$ and aversion toward risk $\left(u^{\prime \prime} \leq 0\right)$, such as found in some positive figures of economic agents in the Wealth of Nations.

5. An intra-individual transformation from the natural point of view into the impartial spectator's point of view, based on "self-command" (Bréban 2014), is successfully carried out for some individuals, and gives rise, along with prudence, to the progressive prevalence of aversion toward risk. This is achieved in spite of the universal tendency which leads to over-value probabilities of success and under-value probabilities of failure.

These propositions perform a sophisticated juncture between elements rooted in Adam Smith's economic and moral works, in which we can acknowledge a complete theory of behavior under risk. 


\section{Acknowledgments}

Previous versions of this paper were discussed on the occasion of several academic events in 2012-2013: HES 2012 Conference in St Catharines (Ontario, Canada); Seminar of the Gredeg in Nice (France), 2012; Workshop on risk in the history of economic analysis in Paris (France), 2013; Seminar of Phare in Paris, 2013. We are particularly indebted for valuable comments to Alain Chateauneuf, Marc-Arthur Diaye, Louis Eeckhoudt, Gilbert Faccarello, Pierre Garrouste, Nathalie Sigot, Peter Wakker and Kazimierz Zaras. The referees of this journal also led us to render explicit our methodological viewpoint. Nonetheless, the usual caveat remains.

\section{References}

M. Allais (1953). Le Comportement de l'Homme Rationnel devant le Risque: Critique des Postulats et Axiomes de l'École Américaine, Econometrica, 21(4), pp. 503-46.

J. Bernoulli (1713). Ars Conjectandi [English translation: The Art of Conjecturing, Baltimore: Johns Hopkins University Press, 2006].

M. Blaug (1962). Economic Theory in Retrospect [5th edition, 1996], Cambridge: Cambridge University Press, 1997.

L. Bréban (2011). Elements for a Moral Theory of Decision: Adam Smith on Happiness and Deliberation, PhD dissertation, Phare, University Paris 1 Panthéon-Sorbonne.

L. Bréban (2012). Sensitivity to Prosperity and Adversity: What Would a Smithian Function of Happiness Look Like?, European Journal of the History of Economic Thought, 19(4), pp. 551-86.

L. Bréban (2014). Smith on Happiness: Towards a Gravitational Theory, European Journal of the History of Economic Thought, 21(3), pp. 359-91.

A. Chateauneuf and M. Cohen (1994). Risk-seeking with Diminishing Marginal Utility in a Non-Expected Utility Model, Journal of Risk and Uncertainty, 9, pp. 77-91.

A. Chateauneuf, M. Cohen and I. Meiljilson (2005). More Pessimism than Greediness: A Characterization of Monotone Risk Aversion in the Rank Dependent Expected Utility Model, Economic Theory, 25, pp. 649-67.

S.-H. Chew, E. Karni and Z. Safra (1987). Risk Aversion in the Theory of Expected Utility with Rank Dependent Preferences, Journal of Economic Theory, 42, pp. 370-81.

M. Cohen (1995). Risk-Aversion Concepts in Expected- and Non-Expected-utility Models, The Geneva Papers on Risk and Insurance Theory, 20, pp. 73-91.

M. Cohen (2015). Risk Perception, Risk Attitude and Decision: a Rank-Dependent Approach, Mathematical Population Studies, 22(1), pp. 53-70.

L. Daston (1988). Classical Probability in the Enlightment, Princeton: Princeton University Press.

M.-A. Diaye and A. Lapidus (2012). Pleasure and Belief in Hume's Decision Process, European Journal of the History of Economic Thought, 19(3), pp. 355-84.

L. Eeckhoudt and H. Schlesinger (2006). Putting Risk in its Proper Place, American Economic Review, 96, pp. $280-89$.

M. J. Goovaerts, F. E. C. De Vylder and J. Haezendonck (1984). Insurance Premiums, Amsterdam: North-Holland.

I. Hacking (1971). Jacques Bernoulli's Art of Conjecturing, British Journal for the Philosophy of Science, 22, pp. 209-29.

J. Hadar and W. R. Russell (1969). Rules for ordering uncertain prospect, American Economic Review, $59(1)$, pp. 25-34. 
G. Hanoch and H. Levy (1969). Efficiency analysis of choices involving risk, Review of Economic Studies, 36(3), pp. 335-46.

S. Hollander (1999). Jeremy Bentham and Adam Smith on the Usury Laws: a 'Smithian' Reply to Bentham and a New Problem, European Journal of the History of Economic Thought, 6(4), pp. 523-51.

D. Hume (1739-1740). A Treatise of Human Nature: Being an Attempt to Introduce the Experimental Method of Reasoning into Moral Subjects, edited by L.A. Selby-Bigge [1888] and P.H. Nidditch [1978], Oxford: Clarendon Press, 1978.

D. Kahneman and A. Tversky (1979). Prospect Theory: An Analysis of Decision under Risk, Econometrica, 47(2), pp. 263-91.

M. S. Kimball (1990). Precautionary Savings in the Small and in the Large, Econometrica, 58, pp. 53-73.

S. Leloup (2000). Pour en Finir avec l'Usure - L'Enjeu de la Controverse entre Adam Smith et Jeremy Bentham, Revue Économique, 51(4), pp. 913-36.

D. M. Levy (1987). Adam Smith's Case for Usury Laws, History of Political Economy, 19(3), pp. 387-400.

D. M. Levy (1999). Adam Smith's Katallactic Model of Gambling: Approbation from the Spectator, Journal of the History of Economic Thought, 21(1), pp. 81-91.

H. Levy (2006). Stochastic Dominance, 2nd edition, New-York: Springer.

M. P. Paganelli (2003). In Medio Stat Virtus : An Alternative View of Usury in Adam Smith's Thinking, History of Political Economy, 35(1), pp. 21-48.

P.-C. Pradier (2006). La Notion de Risque en Économie, Paris: La Découverte.

J. C. Quiggin (1982). A Theory of Anticipated Utility, Journal of Economic Behavior and Organization, 3 , pp. 324-43.

A. Rees (1975). Compensating Wage Differentials, in A. Skinner and T. Wilson (eds), Essays on Adam Smith, Oxford: Clarendon Press, pp. 336-49.

M. Rothschild and J. E. Stiglitz (1970). Increasing Risk: I. A Definition, Journal of Economic Theory, 2, pp. $225-43$.

J. A. Schumpeter (1954). History of Economic Analysis, London: Routledge, 2006.

A. Smith (1759-90). The Theory of Moral Sentiments [ed. by David D. Raphael and Alec L. Macfie], Oxford: Clarendon Press, 1976.

A. Smith (1762-3; 1766). Lectures on jurisprudence [ed. by Ronald L. Meek, David D. Raphael and Peter G. Stein], Oxford: Clarendon Press, 1978.

A. Smith (1776). An Inquiry into the Nature and Causes of the Wealth of Nations [ed. by Roy H. Campbell and Andrew. S. Skinner], Oxford: Clarendon Press, 1976.

A. Smith (1977). The Correspondence of Adam Smith [ed. by Ernest. C. Mossner and Ian S. Ross], Oxford: Clarendon Press, 1977.

P. P. Wakker (2010). Prospect Theory - For Risk and Ambiguity, Cambridge: Cambridge University Press.

G. A. Whitmore (1970). Third-Degree Stochastic Dominance, American Economic Review, 60(3), pp. 457-9.

M. Yaari (1987). The Dual Theory of Choice under Risk, Econometrica, 55, pp. 95-116.

K. Zaras (1989). Dominances Stochastiques pour Deux Classes de Fonctions d'Utilité, Recherche Opérationnelle / Operations Research, 23(1), pp. 57-65. 